\title{
GEOTRAILS IN GREECE
}

\author{
Theodosiou Ir., Athanassouli E., Epitropou N., Janikian Z., Kossiaris G., Michail \\ K., Nicolaou E., Papanikos D., Paschos P., Pavlidou S. and Vougioukalakis G. \\ Institute of Geology and Mineral Exploration (IGME, Spyrou Loui 1, Olympic village, Entrance C, \\ 13677 Acharnai - Greece, ren@igme.gr
}

\begin{abstract}
Planning of walking and motoring geotrails around the geosites, in combination with other attractions of biotic, archaeological and cultural interest, as well as creation of interpretative, awareness printed material relevant to the geosites is one of the objectives of the project "Designation of geosites - geoparks, contribution to sustainable development". It is a project of the Institute of Geology and Mineral Exploration (IGME), funded from the $3^{\text {rd }}$ community support framework program. Furthermore, this printed material which is also available in digital form aided by the project's data base and the geographic information system is used to develop an application for display at the IGME museum, exploiting the potential of multimedia and interactive technologies (e.g.touch screens), in a way that will attract the interest of the visitor on the geological history and at the time entertain him.

Making of the right interpretive products will result in the designation of the geological heritage and the establishment of new forms of alternative tourism, a modern tourist trend which will help in the social and economic development of each region. Designation of geosites will also have a positive impact on the awareness and knowledge of geological history at all levels of education, in our country as well as internationally.
\end{abstract}

Key words: geotrails, geosites, geoparks, geotourism, sustainable development, Greece, Lavrion, Vikos-Aoos, Maroneia, Thassos, W. Crete and Gavdos island, Nissyros island.

\section{Introduction}

The research project objectives have been the designation of Geosites and Geoparks and relevant tasks. In order to accomplish these objectives the project was divided in five sub-projects, running with a differentiation in time from one to another. Thus, needed acquisition and elaboration of data could be accomplished. Mentioned sub-projects are the following:

1.1 Identification, evaluation, classification and systematic registration of greek geosites.

1.2 Compilation of a database (DB) and a Geographic Information System (GIS) for the geosites, geotrails and potential geoparks in the country.

\subsection{Planning of walking and motoring geotrails.}

1.4 Specifications and studies regarding geoparks' operations, interpretation, tourism, marketing, development and management planning. Application dossiers for the European and Global UNESCO geoparks networks. 


\subsection{Production of appropriate material task either for scientific or awareness raising purposes.}

Project research started in May 2006 with a budget of 600.000 E. coordinated by the Department of General Geology and Geological Mapping. Around 25 various professions geoscientists of IGME have been involved, either from the Central Services or from the regional Departments of the Institute. Cooperation with other specialists, eg. archeologists, civil engineers, environmentalists, interpreters, GIS specialists etc. has been also retained from the private domain.

\section{Methodology}

In another paper of this conference we have focussed mostly on the 1.1 sub-project methodology as Geosites registration is the source of information and the infrastructure for the whole research project.

This paper deals with the sub-projects 2.3, 2.3 and 2.5, that is planning of geotrails, the relevant database and GIS, the geotrails cards publication, as well as the informative and the interpretive relevant signs production. It's worth mentioning also that a survey form for geotrails and cards and signs is uploaded at igme site, www.igme.gr. (Theodosiou, 2009). An interactive application on geological heritage, geotrails, geoparks progresses for the Museum at IGME.

\subsection{General}

Applying certain criteria in the Geosites GIS-aided DB, a number of areas with geoparks potential have been revealed.

A geopark is an area with diversity and interest in geosites but also with people, other values, infrastactures existing and/or "builded" gradually, management structures, an information, reception center, activities, events, accommodation places, places to eat, enjoy etc. One or even more isolated geosites, an isolated walk, without opportunity for access, lack of variety, values, density of geosites, lack of other interests in the area, without interest of the local community for tourism development is not a geopark. We cannot have a geopark from zero. Nevertheless geosites should be designated and eventually protected in a physiocratic approach, Geoparks is a more anthropocentric approach and includes economic and social values.

Selection criteria applied in the Database to define areas with geoparks potential and relevant maturity status were:

- Important geoscientific, educational or tourist values representative of the area, its geological history, events or processes.

- Density of geosites.

- Diversity of geosites.

- Other values of the natural and cultural environment.

- Certain extent of the area under concern for tourism activities to take place.

- Existing or under preparation management structures, eg. an information, interpretation center, interpretation on site (informative, interpretive signs etc).

- Existing or under preparation infrastructure and facilities for staying, feeding, entertainment, access.

- Protection status at least partial.

- Interest and cooperation of local people and local authorities.

Information needed to respond to these criteria apparently was entered and elaborated in the Data 
Base from Geosites protocol forms, with sub-project 1.1, filled in with data mostly from field work but also from bibliographic data.

14 areas have been that way defined with geoparks potential for further study, in the framework of the project, the following:

1. Maronia area, 2. S. Thassos island, 3. N.W. Chalkidiki, 4. Olympos area, 5. Vourinos mountain, 6. Meteora, 7. Pindos mountain, 8. Aoos-Vikos area, 9. Kokkinopilos area, 10. Acheron, 11. N. Peloponnisos, 12. Lavreotiki, 13. W. Crete \& Gavdos island, 14. Nisyros inland.

Availability of scientists, time, budget, and technical means gave priority to the following areas for the pilot geotrails design and relevant publication geotrails cards, in order to promote the geoscientific values as well as other interests of these areas:

1. Maronia area, 2. S. Thassos island, 3. Aoos-Vikos area, 4. Kokkinopilos area, 5. Acheron, 6. Lavreotiki, 7. W. Crete \& Gavdos island, 8. Nisyros island.

\subsection{Interpretation}

A number of IGME geoscientists involved in the project undertook the task to design the geotrails, to localize the points for signs to be placed. At the same time a question was the form to present these geotrails and sings in a way to be attractive and interpetive. The material should be attractive in order people to acquire the culture of this new outdoor activity, geotrails. All these new needs required updated knowledge of new concepts and means of communication and interpretation (Page, 1994). The critical point of interpretation revealed.

A first Interpretive Training Course for geoscientists of the Institute of Geology and Mineral Exploration of Greece was organized in December 2007 (Theodosiou, 2007).

\subsubsection{Definitions, principles and concepts of interpretation (Veverka, 1998)}

Within the interpretive profession there are several definitions of what interpretation is. One of the most commonly used definitions of interpretation is that:

Interpretation is a communication process designed to reveal meanings and relationships of our cultural and natural heritage, to visitors, through first hand involvement with objects, artifacts, objects or sites. (Interpretation Canada - 1976).

The American Association for Interpretation defines interpretation as: A communication process that forges emotional and intellectual connections between the interests of the audience and the inherent meanings of the resource.

The main difference between interpretation and information is not what the message or program contains - the information - but how the information is presented. The basics of interpretation principles are:

1. All interpretive efforts must relate to a visitor's personality, experience or interests. This includes tangibles, intangibles and universal concepts as well.

2. Information does not equal interpretation, but all interpretation contains information.

3. Interpretation is an art, which combines many arts regardless of subject material. Any art is to some degree teachable.

4. Interpretation does not equal instruction, but rather provocation. 
5. Interpretation should aim to present a whole rather than a part.

6. Interpretation for children must be designed specifically for children, and not simply a dilution of programs and information for adults (Tilden, 1977).

The communication process used to «interpret» information is based on Interpretive Principles, expressed by Tilden in 1954. Tilden's basic communication principles are also the ones you will find in every first year marketing or advertising textbook on successful communication with your market (audience).

The main Tilden's principles are:

Provoke - attention, curiosity and interest.

Relate - to the everyday life of your visitors.

Reveal - the main concept or theme through some creative or unusual viewpoint.

Address the Whole - make sure your program relates to your main program theme.

Strive for message unity - use the correct supporting elements in your program to illustrate your theme or main concept.

Tilden's principles are based on Learning Concepts (in Veverka, 1998):

- We all bring our pasts to the present.

- Categories can blind us.

- First impressions are especially important.

- Unless helped, we often fail to find, see or comprehend.

- Meanings are in people, not in words.

- My perception is not your perception.

- Circuit overload causes distortion and fatigue.

- Feedback is essential.

- Simplicity and organization clarify messages.

- A picture can be worth than 1000 words (but can be the wrong 1000 words).

\subsubsection{Hands on experience and practicum on interpretation}

Agenda of the interpretive training course included at a first stage three successive workshops that took place in one day with the following issues:

Workshop 1-Concept map: approaching the concept of geological-geomorphological heritage.

Workshop 2- table mat: Geotourism and crucial issues, focused discussion in groups.

Workshop 3- card sort: Geoparks, priorities and scale of actions.

All three workshops attempted to answer the question: why a course on geological heritage interpretation. Discussion at the end of the day was a stimulus for the main course on interpretation in the following days.

The course included theory and practice in the room, as well as at the spot (case study Lavreotiki) training on interpretation issues.

Started with Introduction to heritage interpretation, passed to Planning and design of interpretive media and to Interpretive master planning for heritage/geological sites, parks and facilities.

Armed with first experiences on interpretation concepts, a Field Trip in Lavreotiki and its ancient mines and other geosites in the area for hands-on experience took place. Sites assessment has been preceded in the framework of 1.1.sub-project of the reasrch project. The area is under study for a 
geopark establishment. Famous since ancient times for its substratum, rich in metals and minerals, the region of Laurium became a major metallurgical centre as early as 3000 B.C. approximately, when the first galleries were dug. Laurium provided all the great civilisations of the Aegean with silver, lead and bronze. The importance of the Laurium mines for the city of Athens grew rapidly after the 6th century B.C.

Practicum on site experience to begin an analysis and interpretive planning considerations, started with the depiction of interpretive on the spot signs.

Back in room Interpretive planning practicum for the site visited, to develop the interpretive plan draft for Laurium to include: Specific objectives, Specific theme and storyline flow, Potential visitors and marketing considerations, Begin filling out interpretive planning form sets for inventoried sites, Develop an implementation and operations matrix for putting the plan into action, Discussion for next steps to take (Veverka, 2007). These considerations helped in preparing the specifications and studies of sub-project 1.4.

The interpretive workshop was evaluated by a critical friend (Demertzi, 2007).

While seminar was open only to IGME geoscientists and research project special objectives, an open session on "An interpretation general overview" took also place that gave the opportunity to invite interested people from relevant domains (universities, NGOS, private domain, ministries etc) and have an interesting and feed backing discussion.

\section{3 "Series Geotrails in Greece" Publication}

The series "Geotrails in Greece" (Athanassouli et al, 2009; Epitropou, 2009; Janikian, 2009; Kossiaris, Michail, 2009; Paschos et al; Vougioukalakis, 2009) is a pilot publication (ed. Theodosiou) of IGME, provided in Greek and in English version, for six greek areas: Thassos, Maroneia, Epirus (Vikos, Acheron, Kokkinopilos), Lavreotiki, Nisyros, W. Crete, Gavdos. Supported by GIS-aided DB, it is completed with in situ panels and an interactive application at the Museum of IGME. A survey (evaluation) of the geotrails, the cards and the signs is uploaded currently on www.igme.gr

Each folder of the series contains a number of 12-15 numbered waterproof cards. The $12 \mathrm{cmx} 28 \mathrm{~cm}$ rainproof folder can be hanged in order to let the hands of the hiker free. First cards deal with general issues like: Background on the area, How to use the cards, Useful information (and credits), Code of conduct of the responsible hiker, Warnings. Follow cards briefing the natural, cultural heritage of the area, as well as its geological history, a card present the group of the suggested geotrails in a map, while in the successive cards the suggested geotrails are described severally on a map, a text and photos. In the following paragraphs the general cards, more or less the same in all folders are described, as the rest cards are specific for its area. Photos, sketches, geological maps and sections are included interpreting and decorating the geosites in the cards.

\subsubsection{Background on the area}

The area under concern is presentes briefly focussing on its geological heritage interests, as well as on specific nterests which ourlines its specific character, its physiognomy.

\subsubsection{How to use the cards}

The trails described in the cards have been designed to let us know some key points in the geological history of the area, all intimately connected with its cultural history. The introductory cards 
briefly outline the natural, cultural and geological heritage of the area, while the rest of the cards describe the respective trails.

Some of the routes are designed to be covered by car, whereas others are meant to be completed on foot. Each card describes one route except a few cards which describe more than one shorter routes. The paragraphs that begin with a letter (A, B ...) contain instructions on how to reach a site, whereas the numbered paragraphs $(1,2 \ldots)$ provide mainly information on the geological interest of a location (geosite). The same letters and numbers can be seen on the map.

The maps on the cards are indicative and the information they provide is not exhaustive. The 1:50,000 topographic map is an essential tool for your hike, and you could also use the corresponding geological maps.

Some of the geotrails concentrate on one particular topic, while others cover more than one topics. Several geotrails run along designated trails of the international, national or local network.

The coloured geotrails that are traced on the map (one colour for each trail) are not currently marked on the spot. The geotrails will eventually be marked with signs (initially, with the name of the geosite and, later, with further interpretative information) at the points of interest described in these cards. That is why it is a good idea to observe carefully the route you are covering, for relevant signs. Before you set off, it is also a good idea to read all the commentary in the cards regarding your route. The trails are all relatively easy; when a trail presents a certain difficulty, this is mentioned in the corresponding card. What you need is a car in good condition, appropriate clothing, hiking boots, some equipment (e.g. walking stick, torch...), water, food and good company.

\subsubsection{Useful information. Credits}

This first attempt at tracing geotrails focused on the geotrails running along existing roads or open paths with a minimum of marking. In a few cases, the trails cross private or archaeological sites. Geohikers should behave accordingly in each case, respect the rights of the landowners or the rules of the sites and try to maintain them in the best condition possible.

During the planning of the series, several similar attempts have been used as reference (Flowerdew, Smyth, ed. Mc Keever, 2001; ProGEO Croatia, 2008; Fassoulas et al, 2008; Zouros et al, 2008; Sperrins Tourism limited, 2002).

Credits for the entire work regarding field research, texts, photographs, project coordination, editing, design, coordinating department, copyright, publisher are referred as well.

\subsubsection{Code of conduct of the responsible hiker}

When we hike along a trail, it is a good idea to keep in mind that this is a, public or private, protected area. The environment is a source of health, fitness, pleasure and recreation on condition that we treat it with care. It is, therefore, desirable to follow some basic rules.

- Use a car in good condition, preferably an off-road vehicle.

- Wear clothing that is appropriately warm or cool, depending on the time of the year. Use walking footwear (preferably hiking boots).

- Park carefully so that you do not obstruct entry to or exit from a place.

- Do not damage fences or walls.

- Be careful when lighting fires! If you see fire burning, call the Fire Brigade immediately.

- Do not leave any waste material behind. 
- Avoid aimlessly collecting minerals or fossils. Mineral and fossils are more valuable when encountered in their natural context.

- Use the geologist's hammer wisely.

- If an accident occurs, notify emergency services immediately.

\subsubsection{Warning}

Hikers who wish to cover the trails we propose should know that they are doing so at their own risk. IGME will bear no responsibility for any incident that might occur.

\subsubsection{Where to ask for material provision}

For information, publications, studies and maps on the geology of Greece or of specific Greek regions, contact the Greek Institute of Geology and Mineral Exploration Greek Institute of Geology and Mineral Exploration.

The cards that follow in the folder are specific for its area, thus they are referred by their name but are not described here:

\subsection{7 map of the area of interest with the suggested geotrails}

\subsubsection{Natural and cultural heritage of the area}

\subsubsection{Geology}

\subsubsection{Geotrail 1, 2, etc.}

\subsection{Signs small, big, informative, interpretive}

Geotrails cards are combined with in situ sings (Page, 1994; http://scottishgeology.com/outandabout/geotourism.html). Large informative-interpretive bilingual aluminium signs of $60 \mathrm{cmX} 70 \mathrm{~cm}$ have been designed 3-5 for each geotrails area, to be put in central places of the area. Each one contains a topographic map, with the geotrails in the same colours as in the cards and a small general bilingual text promoting the values and the specific interests of the place. A small text in red colour warns for attention. The title of the project, the logos of IGME, project, the programme are also depicted on the sign. Signs are fixwd on a $2 \mathrm{~m}$ long staff.

Informative small $18 \mathrm{cmX} 21 \mathrm{~cm}$ signs have been produces, one for its geosite at least to be placed along each geotrail and at the very place of the geosite. Each geotrail's small signs are in the same colour with the geotrail on the map of cards and narg signs. In that way one can realize always in which geotrail one is.

Interpretive signs on geosites are to be prepared with the circumstance of a new project.

\subsection{Survey}

Survey-evaluation form of this publication and relevant in spot signs are to be found at IGME website (http://www.igme.gr). There, it is to be found a briefing on the project and the sub-projects. The opinion of those who used the cards as well as suggestions will be very helpful for their improvement.

\subsection{Interactive application}

Supportive to geotrails, geoparks idea but also to geological heritage conservation concept is an ap- 
plication for display at the IGME museum. Exploiting the potential of multimedia and interactive technologies (e.g. touch screens), in a way that will attract the interest of the visitor on the geological history and at the time entertain him, involves in promotion of the idea.

\section{Conclusions-Results}

Planning of geotrails around the geosites, in combination with other attractions of biotic, archaeological and cultural interest, as well as compilation of interpretative, awareness printed material is one of the objectives of the project. Same material in DB and GIS-aided digital form is used for applications, exploiting the potential of multimedia and interactive technologies, to attract the interest of the visitor on the geological history and at the time entertain him.

Creating the right products will result in the designation of the geological heritage and the establishment of new forms of alternative tourism, a modern tourist trend for the social and economic development of each region.

Designating geosites will also have a positive impact on the awareness and knowledge of geological history at all levels of education, in our country and internationally.

\section{Acknowledgments}

I would like to thank all colleagues of IGME infrastructures departments for their cooperation. I would extend my acknowledgments to El. Kleisiouni, to Enveco S.A., to OM-EPE, and to Veverka \& Associates, all collaborators during the project.

\section{References}

Athanassouli, E., Pavlidou, S., Theodosiou, I., 2009. Western Crete and Gavdos island. Series Geotrails in Greece: Ed. Theodosiou, I., (C) IGME, Publ. Kaleidoskopio. ISBN 978-960-98903-0-4 in English and 978-960-87453-4-6 in greek.

Demertzi, V., 2007. Building internal capacity for school improvement and the role of critical friend, Thesis in greek.

Epitropou, N, 2009. Thassos island. Series Geotrails in Greece: Ed. Theodosiou, I., (C) IGME, Publ. Kaleidoskopio. ISBN 978-960-98903-3-5 S. 978-960-87453-7-7 in greek.

Fassoulas, C., Trichas, Ap., Avramakis, M., 2008. The geological heritage of Psiloritis guide. A bilingual publication the of the Psiloritis Natural park. ISBN 978-960-89138-2-0.

Flowerdew, M., Smyth, J.D., 2001. Walk series under the "Landscapes from stone 2001", ed. Mc Keever, P.J. A joint publication by the Geological Survey of Northern Ireland and the Geological Survey of Ireland.

Janikian, Z., 2009. Lavrion and surroundings. Series Geotrails in Greece: Ed. Theodosiou, I., (C IGME, Publ. Kaleidoskopio. ISBN 978-960-98903-2-8 in English and 978-960-87453-6-0 in greek.

Kossiaris, G., Michail, C., 2009. Maroneia area. Geotrails in Greece: Ed. Theodosiou, I., (C IGME, Publ. Kaleidoskopio. ISBN 978-960-98903-4-2 and 978-960-87453-8-4 in greek.

Page, K. 1994. Information signs for geological and geomorphological sites : Basic principles. In O' Halloran, D. Green, C., Harley, M., Stanley, m \& Knill, J. (eds), 1994. Geological and Landscape conservation, Geological Society, London, pp. 433-437.

Paschos, P., Nikolaou, E., Papanikos, D., 2009. Series Geotrails in Greece: Vikos-Aoos and surroundings. Ed. Theodosiou, I., (C) IGME, Publ. Kaleidoskopio. ISBN 978-960-98903-5-9 and 978-960- 
87453-9-1 in greek.

ProGEO Croatia, 2008. Geopark Rab brochures.

Sperrins Tourism limited, 2002: Heritage Pack. www.sperringtourism.com

Theodosiou, I., 2007. Interpretive Training Course for geoscientists of the Institute of Geology and Mineral Exploration of Greece. Progeo NL pgn407, Ed. L. Erikstad.

Theodosiou, I., 2009. Geotrails in Greece, new project results. ProGEO NL pgn 409. Ed. L. Erikstad.

Tilden, Fr. (1977) Interpreting Our Heritage ( $3^{\text {rd }}$ edition). The University of North Carolina Press. Chapel Hill.

Veverka, J., 1998. Interpretive Master Planning. Publ. Acorn Naturalists. California. P. 162. ISBN 1881150-01-1.

Veverka, J., 2007. Interpreting Geological Resources. Workshop Manual for the Greek Institute of Geology and Mineral Exploration seminar. Athens: December 4-7, 2007.

Vougioukalakis, G., 2009. Nisyros island ISBN 978-960-98903-1-1 and 978-960-87453-5-3 in greek.

Zouros, N., Vasileiadou, K., Mantzouka, D., 2008. Lesvos fossilized forest parcs guide in Plaka and Sigri”, and other relevant printed material. Ed. Zouros, N., Mantzouka, D. Publ. Museum of the Lesvos fossilized forest. ISBN 978-960-88364-6-4

http://scottishgeology.com/outandabout/geotourism.html

http://www.igme.gr: Introduction on geotrails sub-project and Survey sheet for geotrails, cards, signs. 